\title{
Using Homework Tip-on as a Post-flipped Learning Tool to Explore Students' Interest, Cognition, and Reuse Intention
}

\author{
Hong Jon-Chao, Tsai Chi-Ruei, and Tai Kai-Wen
}

\begin{abstract}
Flipped learning has become prevalent in current schooling, as it allows students to construct their knowledge in a meaningful way. In contrast to flipped learning, post-flipped learning mainly focuses on reviewing post-class as opposed to previewing pre-class. This study applied Homework Tip-On as a post-flipped learning tool to explore the relationship between internet cognitive fatigue, problem posing cognitive loading, interest and reuse intention. Confirmatory factor analysis was used to verify the reliability and validity of the research instrument, and structural equation modeling was applied to better understand the correlates of students' interest, cognition, and reuse intention. There were 198 effective questionnaires collected and the main results suggested that to evoke the students' reuse intention, we have to reduce the students' problem posing cognitive loading and increase their interest.
\end{abstract}

Index Terms - Internet cognitive fatigue, cognitive loading, post-flipped learning.

\section{INTRODUCTION}

Flipped learning is regarded as a teaching method that may allow students to create meaningful learning opportunities [1] The students preview learning materials before class and conduct a group discussion in the classroom [2]. Based on the concept of flipped learning, post-flipped learning places more focus on the students' after school learning. Homework Tip-On is a game-based learning tool designed to simplify the process of post-flipped learning. The students were asked to review the textbook as a pre-game design task, and then review the electronics engineering concepts through game-based learning.

Previous studies have explored the main factors that affect the user's intention, such as personalization and product type [3], [4]. In recent years, more researchers have focused their attention on the relationship between cognition and reuse intention [5]. These previous studies provide us with empirical evidence that reuse intention might be correlated to individuals' cognition. However, previous researches have not examined the relationship between students' internet cognitive fatigue, problem posing cognitive loading, interest and reuse intention. In this regard, we distributed a questionnaire to vocational high school students who had used Homework Tip-On, to collect data to understand the

Manuscript received September 9, 2015; revised November 22, 2015.

Hong Jon-Chao is with the Department of Industrial Education, National Taiwan Normal University, Taiwan (e-mail: hongjc@ntnu.edu.tw).

Tsai Chi-Ruei and Tai Kai-Wen are with National Taiwan Normal University (e-mail: bass2143@gmail.com, kevintai29@yahoo.com.tw). correlates between those constructs.

\section{LITERATURE REVIEW}

\section{A. Internet Cognitive Fatigue (ICF)}

Fatigue is the state whereby individuals lose focus on what they were concentrating on or fall into a relaxed state after they have completed a hard task for a prolonged period of time; it could be physical, mental, or subjective [6]-[9]. When individuals become fatigued, they may also become inefficient [10].

According to previous studies, the inhibition of individual cognitive functions could be divided into cognitive failure and cognitive fatigue [11], [12]. Cognitive fatigue might cause cognitive disability in relation to one's perception, action and memory capability [13].

\section{B. Problems Posing Cognitive Loading (PPCL)}

The concept of "knowing through learning by doing" points out that the usage or utilization of knowledge might be meaningful to learners [14]. It has become increasingly difficult to evoke students to be engaged in learning tasks through traditional teaching methods such as lecturing. Therefore, involving students in problem posing instead of just answering questions may stimulate their engagement [15]. Problem posing encourages learners to reconstruct their domain knowledge and to assign new meaning when they are posing questions [16]. Problem posing could be divided into free problem-posing situations, semi-structured problemposing situations, and structured problem-posing situations [17]. Some studies have suggested that question posing may increase learners' cognitive loading [18].

\section{Interest}

Interest is regarded as an attitude that makes individuals continue with doing something. If learners are interested in specific subjects, they will have strong motivation, engagement, anticipation and self-concept [19]. Therefore, learning interest can be regarded as a benefit to learners' learning attitude, learning confidence, and ambition [20]. Learning through multimedia can provide students with several meaningful contexts, [21] and along with well-designed information, it can increase learners' interest and be helpful to develop cognition [22].

\section{Reuse Intention}

Technology Acceptance Model (TAM) makes the assumption that individuals take actions or make decisions based on their intention, which might be affected by their 
attitude and subjective norm [23]. It is assumed that attitude toward use of an information system might be related to an individual's behavioral intention to use [24].

\section{RESEARCH DESIGN}

\section{A. Research Participants}

The participants of this study were sophomore university students from the department of electronics engineering. The sample consisted of 192 male and 6 female effective samples. The students have learned the basic concepts of electronics engineering and were ready for the advanced curriculum.

\section{B. Research Tools}

\section{1) Homework tip-on}

Homework Tip-On is a game-based learning app developed by Digital Game-based Learning Lab of National Taiwan Normal University with funding from Taiwan's Ministry of Science and Technology. It is an application that can be used on both Android and iOS. Homework Tip-On allows users to input their well-designed questions into the game authoring system to create games and users have ten different game modes to choose from (see as Fig. 1).
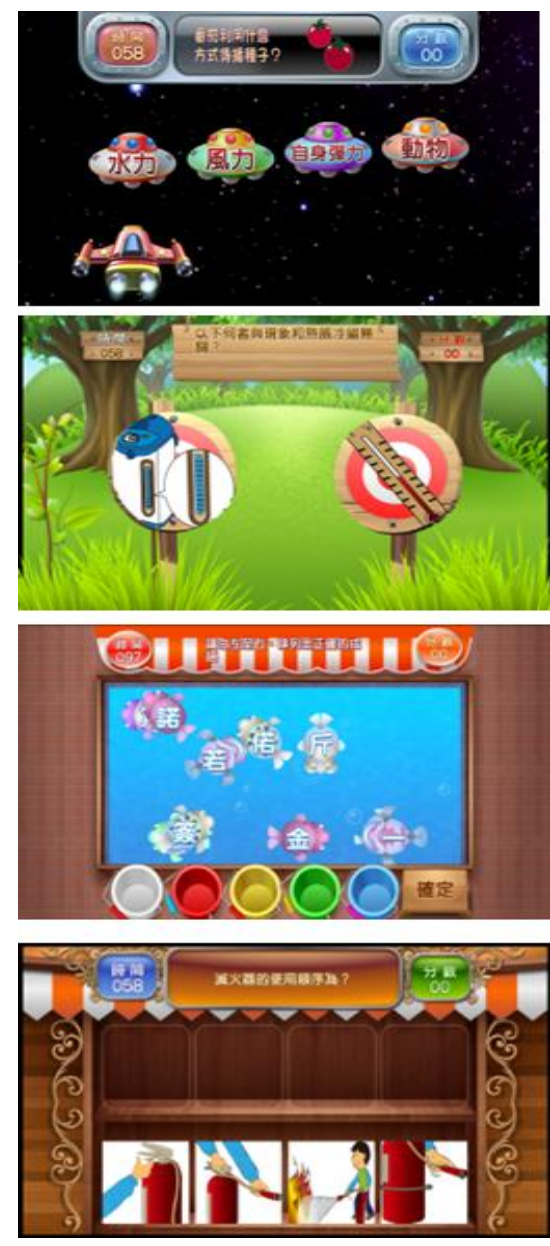

Fig. 1. Screenshots of homework tip-on.

\section{2) Questionnaires}

The questionnaire items were adapted from previous theories or researchers and obtained by professionally translating the original items to Chinese. This research used the five-point Likert scale to compute scores and a self-assessment method, with 1 representing strongly disagree and 5 representing strongly agree.

ICF: Adapted from Hong, Hwang, Liu, Ho, and Chen (2014) who developed a questionnaire with proven validity [25]. PPCL: Items were adapted from Schraw and Dennison (1994) [26]. Interest: Items were adapted from the major types of situational interest [27]. Reuse intention: Items were adapted from Davis (1989) [22].

\section{3) Research procedures}

In the first session of this study, the students were provided with basic materials related to electronics engineering. They were free to ask the teacher any questions or collect other data. In the second session, students were engaged in posing questions, with each student posing 5-10 multiple choice questions. All questions were submitted to the teacher for quality assurance. The third session involved the students using a smart mobile device to play the games their peers had created in Homework Tip-On. In the final session, the students were asked to complete a questionnaire related to this study.

\section{RESEARCH RESULTS}

The analysis was performed in two steps. In the first step, the construct validity and composite reliability were assessed to ensure the reliability and validity. Second, the Pearson's r coefficient of correlation was used to explore the correlation between the constructs.

\section{A. Reliability and Validity Analyses}

The construct validity and composite reliability were used to test the validity. According to Nunnally (1978) [28], a Cronbach's value above .5 indicates an acceptable level of reliability, and according to Fornell and Larcker (1981) [29], the $\mathrm{CR}$ value must be above 0.7 .

There were 135 questionnaires returned and 98 effective questionnaires were analyzed. According to the results, the Cronbach's values in this study were from 0.71 to 0.83 and the $\mathrm{CR}$ values were from 0.77 to 0.83 . The results above showed that the questionnaire items were valid.

\begin{tabular}{lccccc}
\multicolumn{7}{c}{ TABLE I: THE DESCRIPTIVE STATISTIC } \\
\hline Mean & SD & Cronbach's $\alpha$ & CR & AVE \\
\hline ICF & 3.61 & .52 & .51 & .83 & .43 \\
\hline PPCL & 3.45 & .67 & .82 & .77 & .34 \\
\hline interest & 3.40 & .47 & .65 & .83 & .51 \\
\hline $\begin{array}{l}\text { reuse } \\
\text { intention }\end{array}$ & 3.51 & .77 & .83 & .77 & .40 \\
\hline
\end{tabular}

\section{B. Item Analysis}

TABLE II: THE ITEM ANALYSIS

\begin{tabular}{|c|c|c|c|c|c|c|c|}
\hline Items & Mean & SD & & Loading & \multicolumn{3}{|c|}{ t-value } \\
\hline \multicolumn{8}{|l|}{ ICF } \\
\hline ICF-1 & 3.68 & 0.9 & & 0.33 & & 40.02 & \\
\hline ICF-2 & 3.6 & 1 & & 0.35 & & 35.32 & \\
\hline ICF-3 & 3.66 & 1.05 & & 0.72 & & 34.3 & \\
\hline ICF-4 & 3.68 & 1 & & 0.8 & \multicolumn{3}{|c|}{36.03} \\
\hline ICF-5 & \multicolumn{2}{|c|}{3.52} & 1.11 & & 0.88 & & 31.22 \\
\hline ICF-6 & \multicolumn{2}{|c|}{3.75} & 0.88 & & 0.78 & & 41.63 \\
\hline ICF-7 & \multicolumn{2}{|c|}{3.39} & 1.23 & & 0.5 & & 26.87 \\
\hline
\end{tabular}


TABLE III: THE ITEM ANALYSIS

\begin{tabular}{|c|c|c|c|c|c|}
\hline Items & Mean & SD & Loading & $t$-value & \\
\hline \multicolumn{6}{|l|}{ PPCL } \\
\hline PPCL-1 & & 3.35 & 0.95 & 0.46 & 34.55 \\
\hline PPCL-2 & & 3.3 & 0.77 & 0.44 & 42.05 \\
\hline PPCL-3 & & 3.32 & 1.01 & 0.48 & 32.22 \\
\hline PPCL-4 & & 3.73 & 1.01 & 0.7 & 36.17 \\
\hline PPCL-5 & & 3.51 & 0.94 & 0.73 & 36.58 \\
\hline PPCL-6 & & 3.66 & 1.07 & 0.53 & 33.34 \\
\hline PPCL-7 & & 3.27 & 0.91 & 0.65 & 35.15 \\
\hline \multicolumn{6}{|l|}{ interest } \\
\hline interest-1 & & 3.32 & 0.79 & 0.98 & 41.32 \\
\hline interest-2 & & 3.36 & 0.71 & 0.6 & 46.26 \\
\hline interest-3 & & 3.27 & 0.67 & 0.42 & 47.66 \\
\hline interest-4 & & 3.49 & 0.78 & 0.88 & 43.76 \\
\hline interest-5 & & 3.58 & 0.69 & 0.55 & 50.83 \\
\hline \multicolumn{6}{|l|}{$\begin{array}{l}\text { reuse } \\
\text { intention }\end{array}$} \\
\hline $\begin{array}{l}\text { reuse } \\
\text { intention-1 }\end{array}$ & & 3.5 & 1.11 & 0.6 & 30.77 \\
\hline $\begin{array}{l}\text { reuse } \\
\text { intention-2 }\end{array}$ & & 3.54 & 1.09 & 0.63 & 31.98 \\
\hline $\begin{array}{l}\text { reuse } \\
\text { intention-3 }\end{array}$ & & 3.24 & 0.92 & 0.62 & 34.7 \\
\hline $\begin{array}{l}\text { reuse } \\
\text { intention-4 }\end{array}$ & & 3.58 & 0.95 & 0.63 & 37.05 \\
\hline $\begin{array}{l}\text { reuse } \\
\text { intention-5 }\end{array}$ & & 3.68 & 0.95 & 0.66 & 38.09 \\
\hline
\end{tabular}

\section{Correlation Analyses}

The result of Pearson product-moment correlation coefficients are presented in Table I. There were no significant correlations between ICF to PPCL, interest and reuse intention. There was also no significant correlation between interest and PPCL. But the result showed a significant negative correlation between reuse intention and PPCL, and a significant positive correlation between reuse intention and interest.

\section{Model Fit Analysis}

According to Hair et al. (2009) [30], the model fit indexes for the Absolute Fit Measures include the Chi-square, Root Mean Square Error of Approximation (RMSEA), Goodness of Fit Index (GFI), and Adjusted Goodness of Fit Index (AGFI). The overall Absolute Fit Measures in this research were Chi-square $=299.15$; and the degrees of freedom were 184 , which indicated a Chi-square/df $=1.63$, ratio of less than 3 , is considered to be indicative of a good fit (Kline, 2005) [31].

On RMSEA, the threshold value of RMSEA less than .08 is good fit (Hu \& Bentler, 1999) [32]; on GFI, Doll, Xia, and Torkzadeh (1994) [33] indicated the threshold value of GFI above .80 is acceptable; on AGFI, MacCallum and Hong
(1997) [34] suggested the threshold value above .80 is acceptable. In present value of RMSEA was .06 GFI was .85, and AGFI was .81 indicating all fit the threshold value. Incremental Fit Measures in this research were NFI $=.93$, $\mathrm{NNFI}=.95, \mathrm{IFI}=.94, \mathrm{CFI}=.97, \mathrm{RFI}=.91, \mathrm{PCFI}=.84, \mathrm{PNFI}$ $=.79$ and PGFI = .66. Overall, according to Hair et al. (2009), the model fit indexes above showed that the model of this research is acceptable.

TABLE IV: THE CORRELATION MATRIX

\begin{tabular}{|c|c|c|c|c|c|c|}
\hline & ICF & PPCL & interest & & $\begin{array}{l}\text { reuse } \\
\text { intention }\end{array}$ & \\
\hline ICF & & 1 & & & & \\
\hline PPCL & & -0.01 & 1 & & & \\
\hline interest & & -0.19 & -0.04 & 1 & & \\
\hline $\begin{array}{l}\text { reuse } \\
\text { intention }\end{array}$ & & 0.08 & $-0.21^{*}$ & $0.30 * *$ & & 1 \\
\hline
\end{tabular}

\section{E. Path Analysis}

The significance of pathway was identified from each route coefficient's corresponding $t$ value. Fig. 2 shows the results of the path relationship among the hypotheses, revealing that Hypotheses 1 through 5 were supported. Fig. 2 indicated that ICF is significantly related to PPCL $\left(\beta=.492, t=4.914^{* * *}\right)$; ICF is significantly relevant to interest $\left(\beta=-2.91, t=-2.185^{*}\right)$; PPCL is significantly related to interest $(\beta=-.599, t=$ $\left.-3.846^{* *}\right)$; PPCL is significantly related to reuse intention $(\beta$ $=-3.41, t=-2.399 *)$; PPCL is significantly related to reuse intention $(\beta=.442, t=3.194 * *)$.

The explanatory ability of the model is mainly concerned with evaluating whether there are significant route coefficients between each research construct. That is, the predicted ability of the model could be determined by square multiple correlation, $\mathrm{R}^{2}$. The result of this study revealed that the explanation power of PPCL and interest versus reuse intention was $44.9 \%$; the explanation power of PPCL and ICF versus interest was 27.2\%; the explanation power of ICF versus PPCL was $24.3 \%$. The dependent variable in the research showed reasonable predictive ability.

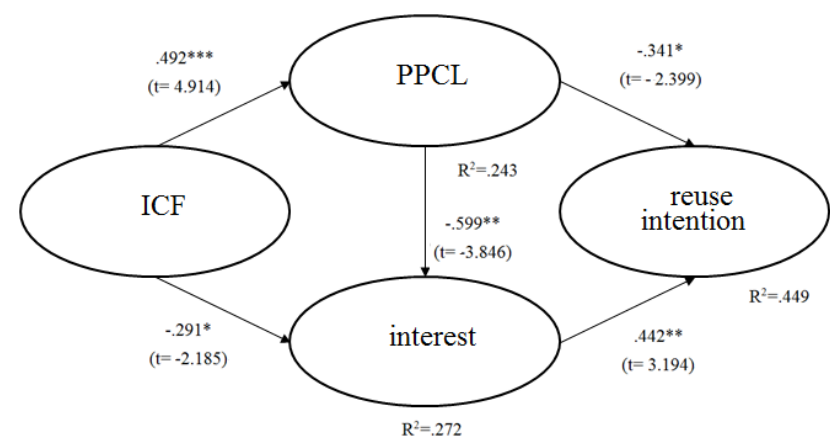

Notes: $* * * p<.001, * * p<.01, * p<.05$

Fig. 2. Verification of research model.

\section{CONCLUSION}

The hypotheses of the study sought to explain the relations between students' internet cognitive fatigue, problem posing cognitive loading, interests and reuse intention when they use Homework Tip-On as a post-flipped learning tool to study electronics engineering. 
The results of this study suggested that to evoke the students' reuse intention, we have to reduce problem posing cognitive loading and increase students' interest. Furthermore, the path analysis suggested that to rise students' reuse intention, the teachers have to decrease students' PPCL and rise their interest. Besides, The less PPCL the students' perceived, they might feel more interested. While PPCL is positively related to ICF and interest is negatively related to ICF.

\section{REFERENCES}

[1] H. L. Chen and K. L. Summers, "Developing, using, and interacting in the flipped learning movement: Gaps among subject areas," The International Review of Research in Open and Distributed Learning, vol. 16, no. 3, 2015.

[2] J. H. Im, Designing a Course for MOOC-Enabled Flipped Learning, No. 2604417, International Institute of Social and Economic Sciences, 2015.

[3] J. Choi, H. J. Lee, and Y. C. Kim, "The influence of social presence on customer intention to reuse online recommender systems: The roles of personalization and product type," International Journal of Electronic Commerce, vol. 16, no. 1, pp. 129-154, 2011

[4] H. J. Lee, M. H. Choi, and M. K. Park, "The effects of self-efficacy and user's cognitive factors on reuse intention of SNS," Journal of the Korean Society for Information Management, vol. 29, no. 3, pp. $145-167,2012$.

[5] I. Mălăescu and S. G. Sutton, "The effects of decision aid structural restrictiveness on cognitive load, perceived usefulness, and reuse intentions," International Journal of Accounting Information Systems, vol. 17, pp. 16-36, 2015.

[6] F. C. Bartlett, "Fatigue following highly skilled work," Nature, vol. 147 , pp. $717-718,1941$.

[7] A. Craig and R. E. Cooper, "Symptoms of acute and chronic fatigue," Handbook of Human Performance, vol. 3, pp. 289-339, 1992.

[8] S. H. Fairclough, "Mental effort regulation and the functional impairment of the driver," Stress, Workload and Fatigue, 2001.

[9] G. Matthews and D. R. Davies, Human Performance: Cognition, Stress, and Individual Differences, Psychology Press, 2000.

[10] R. F. Job and J. Dalziel, "Defining fatigue as a condition of the organism and distinguishing it from habituation, adaptation, and boredom," 2001

[11] S. P. Tipper, "Does negative priming reflect inhibitory mechanisms? A review and integration of conflicting views," The Quarterly Journal of Experimental Psychology: Section A, vol. 54, no. 2, pp. 321-343, 2001.

[12] C. M. MacLeod, Directed Forgetting, NJ: Lawrence Erlbaum Associates Press, 1998, pp. 1-57.

[13] K. H. Schmidt, B. Neubach, and H. Heuer, "Self-control demands, cognitive control deficits, and burnout," Work \& Stress, vol. 21, no. 2, pp. 142-154, 2007.

[14] J. Dewey, Experience and Nature, vol. 1, Courier Corporation, 1958.

[15] S. A. Barab, M. S. Gresalfi, T. Dodge, and A. Ingram-Goble, "Narratizing disciplines and disciplinizing narratives: Games as 21st century curriculum," International Journal for Gaming and Computer-Mediated Simulations, vol. 2, no. 1, pp. 17-30.

[16] E. Stoyanova and N. F. Ellerton, A Framework for Research into Students' Problem Posing in School Mathematics, Melbourne, Australasia: Mathematics Education Research Group.

[17] B. Southwell, "Problem solving through problem posing: The experience of two teacher education students," in Proc. MERGA Conference, 1998, pp. 221-245.
[18] C. G. Schloemer, Integrating Problem Posing into Instruction in Advanced Algebra: Feasibility and Outcomes, 1994.

[19] J. L. Wilkins, "Mathematics and science self-concept: An international investigation," The Journal of Experimental Education, vol. 72, no. 4 pp. 331-346, 2004.

[20] K. R. Wentzel and A. Wigfield, "Academic and social motivation influences on student's academic performance," Education Psychology Review, vol. 10, pp. 155-174, 1998.

[21] P. A. Ertmer and T. J. Newby, "Behaviorism, cognitivism, constructivism: Comparing critical features from an instructional design perspective," Performance Improvement Quarterly, vol. 6, no. 4, pp. 50-72, 1993

[22] R. E. Mayer, "Cognitive theory of multimedia learning," The Cambridge Handbook of Multimedia Learning, NY: Cambridge University Press, 2005.

[23] F. D. Davis, "Perceived usefulness, perceived ease of use, and acceptance of information technology," MIS Quarterly, vol. 13, no. 3, pp. 319-340, 1989

[24] V. Venkatesh and H. Bala, "Technology acceptance model 3 and a research agenda on interventions," Decision Sciences, vol. 39, no. 2 , pp. 273-315, 2008

[25] J. C. Hong, M. Y. Hwang, K. S. Tai, and Y. L. Chen, "The design of calibration to enhance self-confidence in English vocabulary learning by means of mobile devices," Computer \& Education, vol. 72, pp. 313-322, 2014.

[26] G. Schraw and R. S. Dennison, "Assessing metacognitive awareness," Contemporary Educational Psychology, vol. 19, no. 4, pp. 460-475, 1994.

[27] J. Rotgans and H. Schmidt, "Examination of the context-specific nature of self-regulated learning," Educational Studies, vol. 35, no. 3, pp. 239-253, 2009

[28] J. C. Nunnally, Psychometric Theory, New York: McGraw-Hill, 1978

[29] C. Fornell and D. F. Larcker, "Evaluating structural equation models with unobservable variables and measurement error," Journal of Marketing Research, vol. 39, no. 1, pp. 39-50, 1981

[30] J. Hair, B. Black, B. Babin, R. E. Anderson, and R. L. Tatham, Multivariate Data Analysis, NJ: Prentice Hall, 2009.

[31] R. B. Kline, Principles and Practice of Structural Equation Modeling, NY: Guilford, 2005.

[32] L. Hu and P. M. Bentler, "Cutoff criteria for fit indexes in covariance structure analysis: Conventional criteria versus new alternatives," Structural Equation Modeling: A Multidisciplinary Journal, vol. 6, no. 1 , pp. 1-55, 1999.

[33] W. J. Doll, W. Xia, and G. Torkzadeh, "A confirmatory factor analysis of the end-user computing satisfaction instrument," MIS Quarterly, vol. 18, no. 4, pp. 453-461, 1994.

[34] R. C. MacCallum and S. Hong, "Power analysis in covariance structure modeling using GFI and AGFI," Multivariate Behavioral Research, vol. 32, no. 2, pp. 193-210, 1997.

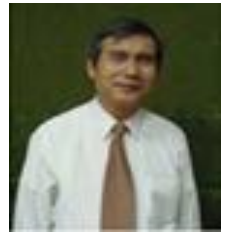

Hong Jon-Chao was born on January 12, 1951 in Taipei, Taiwan. He received his doctoral degree in education from the University of Illinois, Champaign-Urbana. He is currently a chair professor in the Department of Industrial Education in National Taiwan Normal University. His current research focuses on e-learning, game-based learning, and hands-on learning. He has developed many APPs to encourage game-based learning, and has also devoted himself to hold "STEAM" (science, technology, engineering, art, and mathematics) contests, such as PowerTech, World Creative Robot Contest (known as GreenMech before 2014), and International Exhibition for Young Inventor (IEYI). 